\title{
A RESEARCH OF THE INDUSTRY STRUCTURE IN CHINA: BASED ON STRUCTURAL DECOMPOSITION TECHNIQUE OF INPUT-OUTPUT MODEL
}

\author{
Ma Yiming \\ School of economics and management, Nanjing University of \\ Aeronautics and Astronautics, Jiangsu 211106, China
}

DOI: 10.46609/IJSSER.2020.v05i03.003 URL: https://doi.org/10.46609/IJSSER.2020.v05i03.003

\begin{abstract}
Based on the input-output model, this paper divides the industrial structure effect into three parts: multiplier effect, feedback effect and spillover effect, and analyzes the relevance of 42 industries in China in 2017 with the input-output table. The research shows that the spillover effect, multiplier effect and feedback effect of Chinese industry are decreasing in order. For the development of China's industry, to enhance the industry's self-development ability and optimize the industrial relationship is the fundamental to promote the transformation of China's industry.
\end{abstract}

Keywords: Structural decomposition, Self-development ability, Response ability, Influence ability

\section{INTRODUCTION}

Industrial structure change is an important variable of national economic development. In the important period of China's economic and social transformation, industrial structure optimization is particularly important. In order to study the optimization of industrial structure, it is necessary to reveal the economic relationship and dependence relationship between industries, which is the industry correlation. Considering that the input-output analysis method is one of the most important methods to study the industry correlation, this paper analyzes the industry correlation of China with the input-output analysis method, which provides an important basis for understanding the technical relevance characteristics of China's industries, and also has a certain reference value for effectively promoting the transformation and development of China's domestic industries.

MODEL 
International Journal of Social Science and Economic Research

ISSN: $2455-8834$

Volume: 05, Issue: 03 "March 2020"

The input-output analysis method has been widely used in the field of industry correlation analysis. Some studied it from the perspective of industry as a whole, such as $\mathrm{Li} \& \mathrm{Hu}(2008)$, Liu et al. (2010) and Gao (2008). Some studied it based on a single industry, such as Wang \& Liu (2004) on the driving ability of real estate industry to related industries, and Song (2007) on the industry correlation of tourism. And many scholars use input-output analysis method as a tool to measure environmental costs, energy consumption, carbon emissions and other indicators, such as Li et al. (2018), Sun et al. (2010), Liang et al. (2007), Zhang \& Liu (2013). In this paper, from the perspective of the overall economy, referring to the structural decomposition technology adopted by $\mathrm{Yu}$ et al. (2011), the correlation characteristics of China's industrial structure are analyzed.

Miller \& Blair (1985) has expanded the technology of structural decomposition of input-output model. They regard all sectors of one country as an independent element in a multi-national and multi sector input-output model, and carry out structural decomposition of the model. Referring to their ideas, this paper will take one sector as an independent element in a multi sector inputoutput model of one country, and analyze the structure of the model. Similar to Miller \& Blair (1985), the Leontief inverse matrix can be decomposed into the following forms:

$\left(\begin{array}{cccc}b_{11} & b_{12} & \cdots & b_{1 \mathrm{n}} \\ b_{21} & b_{22} & \cdots & b_{2 \mathrm{n}} \\ \cdots & \cdots & \cdots & \cdots \\ b_{n 1} & b_{n 2} & \cdots & b_{n n}\end{array}\right)=\left(\begin{array}{ccccc}\frac{1}{1-a_{11}} & \frac{1}{1-a_{12}} & \cdots & \frac{1}{1-a_{1 n}} \\ \frac{1}{1-a_{21}} & \frac{1}{1-a_{22}} & \cdots & \frac{1}{1-a_{2 n}} \\ \cdots & \cdots & \cdots & \cdots \\ \frac{1}{1-a_{n 1}} & \frac{1}{1-a_{n 2}} & \cdots & \frac{1}{1-a_{n n}}\end{array}\right)$
$+\left(\begin{array}{ccccc}b_{11}-\frac{1}{1-a_{11}} & b_{12}-\frac{1}{1-a_{12}} & \cdots & b_{1 n}-\frac{1}{1-a_{1 n}} \\ b_{21}-\frac{1}{1-a_{21}} & b_{22}-\frac{1}{1-a_{22}} & \cdots & b_{2 n}-\frac{1}{1-a_{2 n}} \\ \cdots & \cdots & \cdots \\ b_{n 1}-\frac{1}{1-a_{n 1}} & b_{n 2}-\frac{1}{1-a_{n 2}} & \cdots & b_{n n}-\frac{1}{1-a_{n n}}\end{array}\right)+\left(\begin{array}{cccc}0 & b_{12} & \cdots & b_{1 n} \\ b_{21} & 0 & \cdots & b_{2 n} \\ \cdots & \cdots & \cdots & \cdots \\ b_{n 1} & b_{n 2} & \cdots & 0\end{array}\right)$

In (1), $\mathrm{A}=\left(a_{i j}\right)_{n \times n}$ is the direct consumption coefficient matrix, and $\mathrm{B}=\left(b_{i j}\right)_{n \times n}$ is the Leontief inverse matrix. For the industrial sector $\mathrm{i}$, there is the following equation:

$$
X_{i}=\frac{1}{1-a_{i i}} Y_{i}+\left(b_{i i}-\frac{1}{1-a_{i i}}\right) Y_{i}+\sum_{j, j \neq i}^{n} b_{i j} Y_{J}
$$


In (2), $X_{i}$ is the total product of industrial sector i and $Y_{i}$ is the ultimate product of industrial sector $i$. The meaning of inverse matrix coefficient of input-output is the sum of direct and indirect output changes caused by the change of production unit in an industrial sector, so (2) shows that the total output of industrial sector i consists of three parts. For the convenience of analysis, we define these parts with the ultimate product.

$$
M_{i}=\frac{1}{1-a_{i i}}
$$

$M_{i}$ is the multiplier effect within the industrial sector i, which means the change of the total output of the industrial sector i caused by one unit of change of the ultimate product of industrial sector i. It is the influence of the industry's own demand on its own output, reflecting the industry's self-regulation and sustainable development ability, which is called the selfdevelopment ability in this paper.

$$
F_{i}=b_{i i}-\frac{1}{1-a_{i i}}
$$

$F_{i}$ is the feedback effect of the industrial sector $i$, which means the change of the total output of the industrial sector i caused by the change of other industrial sectors which are caused by one unit of change of the ultimate product of industrial sector i.

$$
S_{1 i}=\sum_{j, j \neq i}^{n} b_{i j}
$$

$S_{1 i}$ is the spillover effect I of the industrial sector i, which means the change of the total output of the industrial sector i caused by one unit of change of the ultimate product of all other industrial sectors. It reflects the response ability of the industrial sector i.

$$
S_{2 i}=\sum_{j, j \neq i}^{n} b_{j i}
$$

Likewise, $S_{2 i}$ is defined as the spillover effect II of the industrial sector $\mathrm{i}$, which means the 
International Journal of Social Science and Economic Research

ISSN: $2455-8834$

Volume: 05, Issue: 03 "March 2020"

change of the sum of the total output of all industrial sectors except the industrial sector i caused by one unit of change of the ultimate product of industrial sector i. It reflects the influence ability of the industrial sector $i$.

In this paper, $M_{i}, F_{i}$ and $S_{1 i}$ reflect the development ability of the industrial sector $\mathrm{i}$, while $S_{1 i}$ and $S_{2 i}$ reflect the correlation between the industrial sector i and all other sectors.

Through this kind of decomposition, we can easily distinguish the industrial structure sources of economic growth of a sector. This kind of structural decomposition is essentially an improvement of the traditional industry correlation analysis. First of all, it decomposes the industrial technological and economic relations into the internal and inter industrial relations, which is of great significance for us to understand the characteristics of industrial relations. We can observe how much industrial growth originates from itself and how much is affected by other sectors through quantitative analysis. Secondly, spillover effect $I$ is a reflection of the influence exerted on a sector by all other sectors, which is similar to the sensitivity coefficient while the Spillover Effect II is similar to the influence coefficient of the sector. But the spillover effect here peels off the influence of the sector itself and truly reflects the relationship between industries, which is more reasonable than the traditional sensitivity coefficient and influence coefficient.

Based on the above model, this paper uses the relevant data of input-output table to measure the correlation effect of China's industrial structure. The calculation is based on the data in the inputoutput table which consists of 149 sectors in 2017 released by the National Bureau of statistics of the People's Republic of China. For the purpose of research, this paper merge the 149 sectors into 42 according to the Industrial classification foe national economic activities (GB/T4754-2017). The sectors includes agricultural sector (primary industry), 27 secondary industry sectors and 14 tertiary industry sectors. This paper analyzes the structure of China's industrial sector based on this new input-output table.

\section{RESULTS}

Using the input-output structure decomposition model corresponding to (2), this paper calculates the effects of China's industries. The results are shown in Table 1. 
International Journal of Social Science and Economic Research

ISSN: $2455-8834$

Volume: 05, Issue: 03 "March 2020"

Table 1: The effects of China's industries. Weighted average based on the proportion of output of each sector.

\begin{tabular}{lccccc}
\hline \multicolumn{1}{c}{ Effects } & $\begin{array}{c}\text { Multiplier } \\
\text { Effect }\end{array}$ & $\begin{array}{c}\text { Feedback } \\
\text { Effect }\end{array}$ & $\begin{array}{c}\text { Spillover } \\
\text { Effect I }\end{array}$ & $\begin{array}{c}\text { Total } \\
\text { Effect }\end{array}$ & $\begin{array}{c}\text { Spillover } \\
\text { Effect II }\end{array}$ \\
\hline Average value of primary industry & 1.154 & 0.073 & 3.419 & 4.646 & 0.801 \\
\hline Average value of secondary industry & 1.345 & 0.035 & 2.262 & 3.642 & 1.781 \\
\hline Average value of tertiary industry & 1.068 & 0.023 & 2.002 & 3.092 & 1.097 \\
\hline Average value of 42 sectors & 1.239 & 0.032 & 2.227 & 3.498 & 1.493 \\
\hline Total value of 42 sectors & 49.892 & 0.913 & 63.253 & 114.058 & 63.253 \\
\hline
\end{tabular}

Assuming that the final demand of 42 sectors in China increases by 100 million yuan, in 2017, the total multiplier effect of all sectors in China's economy is 49.892 , the feedback effect is 0.913 , and the spillover effect I is 63.253 , which means that the output increment that can be created through the industrial self-development is 4.9892 billion yuan, the output growth through the industrial feedback is 0.0913 billion yuan, the added value of output created through the industrial linkage is 6.3253 billion yuan, and the whole economic output will increase by 11.4058 billion yuan. The contribution of multiplier effect is $43.74 \%$, the feedback effect is $0.80 \%$, and the spillover effect is $55.46 \%$. From this point of view, the most critical role of economic growth is the spillover effect, followed by the multiplier effect, and the feedback effect is relatively weak. From the comparison of various effects among the three industries in 2017, in terms of self-development capacity, the second industry $>$ the first industry $>$ the third industry; in terms of feedback capacity, the first industry $>$ the second industry $>$ the third industry; in terms of sensing capacity, the first industry $>$ the second industry $>$ the third industry; in terms of impact, the second industry $>$ the third industry $>$ the first industry. Generally speaking, all kinds of effect values of the secondary industry are basically above the social average level, and all kinds of effect values of the tertiary industry are lower than the social average level. Therefore, the development of the secondary industry plays an important role in the growth of China's overall industry, while the development of the tertiary industry mainly depends on the promotion of other industries.

From the perspective of various effects within the three industries, the development of the three industries is mainly driven by the relevance of other industries, followed by the self-development ability, and the impact of feedback ability is relatively small. In terms of relevance, the response effect on other industries is higher than the influence effect, and there are some differences among the three. In 2017, the multiplier effect of the primary industry was 1.154, the feedback effect was 0.073 , the spillover effect I was 3.419, and the Spillover Effect II of the primary 


\section{International Journal of Social Science and Economic Research}

ISSN: $2455-8834$

Volume: 05, Issue: 03 "March 2020"

industry was 0.801 , which means the final demand of the primary industry increased by 100 million yuan will lead to the output of other industries increased by 80.1 million yuan. Therefore, the importance of other industries for the development of the primary industry is far greater than the primary industry for the development of other industries. Although the response effects of the secondary and tertiary industries is also higher than the influence effect, the gap between them is not as large as that of the primary industry.

The effects of all 42 sectors are shown in Table 2.

Table 2: The effects of China's 42 sectors.

\begin{tabular}{|c|c|c|c|c|c|}
\hline Effects & $\begin{array}{l}\text { Multiplier } \\
\text { Effect }\end{array}$ & $\begin{array}{l}\text { Feedback } \\
\text { Effect }\end{array}$ & $\begin{array}{l}\text { Spillover } \\
\text { Effect I }\end{array}$ & $\begin{array}{l}\text { Total } \\
\text { Effect }\end{array}$ & $\begin{array}{l}\text { Spillover } \\
\text { Effect II }\end{array}$ \\
\hline $\begin{array}{l}\text { Farming, Forestry, Animal Production } \\
\text { and Fishery }\end{array}$ & 1.154 & 0.073 & 3.419 & 4.646 & 0.801 \\
\hline Mining and Washing of Coal & 1.185 & 0.022 & 1.597 & 2.805 & 1.060 \\
\hline $\begin{array}{l}\text { Extraction of Crude Petroleum and } \\
\text { Natural Gas }\end{array}$ & 1.007 & 0.017 & 2.179 & 3.203 & 0.886 \\
\hline Mining of Metal Ores & 1.130 & 0.016 & 1.248 & 2.394 & 1.338 \\
\hline $\begin{array}{l}\text { Mining and Quarrying of Nonmetallic } \\
\text { Mineral and Other Mineral }\end{array}$ & 1.019 & 0.012 & 0.695 & 1.726 & 1.550 \\
\hline Manufacture of Food and Tobacco & 1.272 & 0.081 & 2.409 & 3.762 & 1.450 \\
\hline Manufacture of Textiles & 1.598 & 0.014 & 1.469 & 3.081 & 1.750 \\
\hline $\begin{array}{l}\text { Manufacture of Textile Wearing } \\
\text { Apparel, Footwear, Leather, Fur, Feather } \\
\text { and Its Products }\end{array}$ & 1.160 & 0.010 & 0.554 & 1.725 & 2.306 \\
\hline $\begin{array}{l}\text { Processing of Timbers and Manufacture } \\
\text { of Furniture }\end{array}$ & 1.488 & 0.005 & 0.431 & 1.923 & 1.740 \\
\hline $\begin{array}{l}\text { Papermaking, Printing and Manufacture } \\
\text { of Articles for Culture, Education and } \\
\text { Sports Activities }\end{array}$ & 1.343 & 0.021 & 1.347 & 2.710 & 1.823 \\
\hline $\begin{array}{l}\text { Manufacture of Refined Petroleum, } \\
\text { Coke Products, Processing of Nuclear } \\
\text { Fuel }\end{array}$ & 1.074 & 0.027 & 1.908 & 3.009 & 1.501 \\
\hline $\begin{array}{l}\text { Manufacture of Chemicals and Chemical } \\
\text { Products }\end{array}$ & 1.670 & 0.072 & 6.952 & 8.694 & 1.452 \\
\hline
\end{tabular}


International Journal of Social Science and Economic Research

ISSN: 2455-8834

Volume: 05, Issue: 03 "March 2020"

\begin{tabular}{lccccc}
$\begin{array}{l}\text { Manufacture of Nonmetallic Mineral } \\
\text { Products }\end{array}$ & 1.230 & 0.012 & 0.992 & 2.234 & 1.727 \\
\hline Manufacture and Processing of Metals & 1.394 & 0.049 & 4.629 & 6.071 & 1.613 \\
\hline $\begin{array}{l}\text { Manufacture of Fabricated Metal } \\
\text { Products, Except Machinery and } \\
\text { Equipment }\end{array}$ & 1.157 & 0.020 & 1.466 & 2.644 & 2.034 \\
\hline $\begin{array}{l}\text { Manufacture of General-Purpose } \\
\text { Machinery }\end{array}$ & 1.288 & 0.032 & 1.435 & 2.755 & 2.099 \\
\hline $\begin{array}{l}\text { Manufacture of Special-Purpose } \\
\text { Machinery }\end{array}$ & 1.159 & 0.018 & 0.864 & 2.041 & 2.215 \\
\hline Manufacture of Transport Equipment & 1.465 & 0.026 & 1.458 & 2.949 & 1.945 \\
\hline $\begin{array}{l}\text { Manufacture of Electrical Machinery } \\
\text { and Apparatus }\end{array}$ & 1.201 & 0.038 & 1.739 & 2.978 & 2.284 \\
\hline $\begin{array}{l}\text { Manufacture of Communication } \\
\text { Equipment, Computer and Other }\end{array}$ & 2.081 & 0.063 & 2.860 & 5.004 & 1.805 \\
Electronic Equipment & 1.189 & 0.011 & 0.488 & 1.688 & 2.246 \\
\hline Manufacture of Measuring Instruments & 1.028 & 0.002 & 0.142 & 1.172 & 2.209 \\
\hline Other Manufacture & 1.120 & 0.001 & 0.484 & 1.605 & 0.172 \\
\hline Scrap and Waste & 1.001 & 0.002 & 0.069 & 1.071 & 2.405 \\
\hline $\begin{array}{l}\text { Repair of Fabricated Metal Products, } \\
\text { Machinery, and Equipment }\end{array}$ & 1.399 & 0.041 & 3.216 & 4.655 & 1.379 \\
\hline $\begin{array}{l}\text { Production and Supply of Electricity and } \\
\text { Steam }\end{array}$ & 1.145 & 0.002 & 0.181 & 1.328 & 1.461 \\
\hline Production and Distribution of Gas & 1.053 & 0.001 & 0.069 & 1.123 & 1.383 \\
\hline \begin{tabular}{l} 
Production and Distribution of Water \\
\hline Construction
\end{tabular} & 1.033 & 0.002 & 0.145 & 1.180 & 2.124 \\
\hline Wholesale and Retail Trade & 1.006 & 0.022 & 3.625 & 4.653 & 0.775 \\
\hline Transport, Storage and Post & 1.121 & 0.040 & 3.606 & 4.767 & 1.236 \\
\hline $\begin{array}{l}\text { Accommodation, Food and Beverage } \\
\text { Services }\end{array}$ & 0.014 & 1.105 & 2.122 & 1.583 \\
\hline $\begin{array}{l}\text { Information Transmission, Software and } \\
\text { Information Technology Services }\end{array}$ & 1.196 & 0.012 & 0.887 & 2.095 & 1.023 \\
\hline Finance & 0.041 & 3.409 & 4.542 & 0.861 \\
\hline Real Estate & 0.020 & 1.410 & 2.465 & 0.521 \\
\hline \begin{tabular}{l} 
Renting and Leasing, Business Services \\
\hline
\end{tabular} & 0.055 & 2.949 & 4.116 & 1.630 \\
\hline
\end{tabular}


International Journal of Social Science and Economic Research

ISSN: $2455-8834$

Volume: 05, Issue: 03 "March 2020"

\begin{tabular}{lccccc}
$\begin{array}{l}\text { Scientific Research and Development, } \\
\text { Technical Services }\end{array}$ & 1.127 & 0.008 & 0.626 & 1.761 & 1.566 \\
\hline $\begin{array}{l}\text { Management of Water Conservancy, } \\
\text { Environment and Public Facilities }\end{array}$ & 1.035 & 0.002 & 0.214 & 1.251 & 1.451 \\
\hline $\begin{array}{l}\text { Services to Households, Repair and } \\
\text { Other Services }\end{array}$ & 1.020 & 0.006 & 0.616 & 1.642 & 1.264 \\
\hline Education & 1.012 & 0.000 & 0.059 & 1.071 & 0.706 \\
\hline $\begin{array}{l}\text { Health Care and Social Work Activities } \\
\text { Culture, Sports and Entertainment }\end{array}$ & 1.005 & 0.000 & 0.035 & 1.041 & 1.715 \\
\hline $\begin{array}{l}\text { Public Management, Social Security and } \\
\text { Social Organization }\end{array}$ & 1.025 & 0.000 & 0.053 & 1.078 & 0.975 \\
\hline
\end{tabular}

When the final demand of all sectors in the economy increases by 100 million yuan, there is a big gap in the growth due to the differences in the related characteristics of various industries. In terms of total effect, in 2017, the growth of Manufacture of Chemicals and Chemical Products was the biggest, with output added 869.4 million yuan, while the growth of health and social work was the smallest, with output added 104.1 million yuan .Under the stimulation of the demand of the same unit, there are 10 industries whose output increment is above the average level (349.8 million yuan), including 1 primary industry sector, 5 secondary industry sectors and 4 tertiary industry sectors, and the output increment of the secondary industry is relatively high, which means the total effects of the secondary industry is relatively high.

In terms of multiplier effect, in 2017, 10 sectors such as Manufacture of Communication Equipment, Computer and Other Electronic Equipment were higher than the social average level (1.239), and these 10 sectors are all secondary industry sectors. It is not difficult to reach a conclusion that the self-development capacity of the secondary industry is relatively strong in China's economy. Except Information Transmission, Software and Information Technology Services, the multiplier effect ranking of the tertiary industry is lower than 20 , so it can be seen that the self-development capacity of the tertiary industry is weak.

The importance of feedback effect is relatively low. In 2017, the sector with the highest proportion of feedback effect in the total effect is Farming, Forestry, Animal Production and Fishery, which is the first industry, with only $1.57 \%$ of the total. Therefore, the impact of feedback effect on the development of various industries is weak.

There are 10 sectors whose spillover effect I is higher than the social average (2.227), including 
1 primary industry, 5 secondary industry and 4 tertiary industry, and the output increment of the secondary industry is relatively high. It can be seen that the secondary industry has a slightly higher sensitivity to other industries than the tertiary industry. In addition, the spillover effect I of 20 sectors is less than 1, including Construction, Education, etc. They have weak response ability to other industries.

There are 22 sectors whose Spillover Effect II is higher than the social average (1.493), among which only 4 are tertiary industries and the rest are secondary industries. And Farming, Forestry, Animal Production and Fishery rank 38th. It can be seen that the secondary industry has a strong influence on other industries, while the first and third industries have a weak influence. In addition, the spillover effect of 8 sectors is less than 1, including Real Estate. These sectors have weak influence on others, which is also a problem worthy of attention in the development of China's industry.

In order to have a clearer understanding of China's industrial structure, this paper classifies sectors according to the above effects. As the calculation results show that the feedback effect value of each sector is small, and the feedback ability is much less important than other sectors' development ability, so we do not consider the feedback effect when classifying. In this way, the growth of an industry can be characterized by multiplier effect and spillover effect I, while the industry correlation can be represented by spillover effect I and Spillover Effect II. Comparing the effects of various sectors with the corresponding average level, we can make a simple classification of various sectors, as shown in Table 3.

Table 3: Classification of sectors according to $M, S_{1}, S_{2}$

\begin{tabular}{ll}
\hline M-S1-S2 & \\
& \\
& secondary industry : \\
& Mining and Washing of Coal, \\
& Extraction of Crude Petroleum and Natural Gas, \\
& Mining of Metal Ores, \\
& Scrap and Waste, \\
& Production and Distribution of Gas, \\
& Production and Distribution of Water \\
& tertiary industry : \\
& Information Transmission, Software and Information \\
\hline
\end{tabular}


Technology Services,

Real Estate,

Management of Water Conservancy, Environment and Public Facilities,

Services to Households, Repair and Other Services,

Education,

Culture, Sports and Entertainment,

Public Management, Social Security and Social

Organization secondary industry :

Mining and Quarrying of Nonmetallic Mineral and

Other Mineral,

Manufacture of Textile Wearing Apparel, Footwear,

Leather, Fur, Feather and Its Products,

Manufacture of Refined Petroleum, Coke Products,

Processing of Nuclear Fuel,

Manufacture of Nonmetallic Mineral Products,

Manufacture of Fabricated Metal Products, Except

Machinery and Equipment,

Manufacture of Special-Purpose Machinery,

Low-low-high Manufacture of Electrical Machinery and

Apparatus,

Manufacture of Measuring Instruments,

Other Manufacture,

Repair of Fabricated Metal Products, Machinery, and

Equipment,

Construction

tertiary industry :

Accommodation, Food and Beverage Services,

Scientific Research and Development, Technical

Services,

Health Care and Social Work Activities

\section{primary industry :}

Low-high-low Farming, Forestry, Animal Production and Fishery

tertiary industry: 
Wholesale and Retail Trade,

Transport, Storage and Post,

Finance

\begin{tabular}{cl}
\hline Low-high-high & tertiary industry: \\
& Renting and Leasing, Business Services \\
\hline High-low-low & - \\
\hline & secondary industry: \\
& Manufacture of Textiles, \\
& Processing of Timbers and Manufacture of \\
& Furniture, \\
& Papermaking, Printing and Manufacture of Articles \\
High-low-high & for Culture, Education and Sports Activities, \\
& Manufacture of General-Purpose Machinery, \\
& Manufacture of Transport Equipment \\
\hline High-high-low & secondary industry: \\
& Manufacture of Food and Tobacco, \\
& Manufacture of Chemicals and Chemical Products, \\
& Production and Supply of Electricity and Steam \\
\hline & secondary industry: \\
& Manufacture and Processing of Metals, \\
& Manufacture of Communication Equipment, \\
High-high-high & Computer and Other Electronic Equipment \\
\hline
\end{tabular}

The primary industry belongs to the third category, which has poor self-development ability and influence ability. However, due to its strong response ability, the industry has certain growth. Therefore, for the first industry, for the first industry, to improve the development mechanism, improve the technical level, optimize the agricultural structure, so as to improve the spillover effect on other sectors, which is not only good to the improvement of the primary industry's selfdevelopment ability, but also to improve its influence ability, which has a huge role in promoting the secondary and tertiary industries.

The composition of the secondary industry is complex. 6 sectors including Scrap and Waste belong to the first category, with poor growth and weak correlation, which shows that these sectors have strong independence, and most of them belong to monopoly industries. 11 sectors including Construction belong to the second category. Their growth is poor, but they have a 


\section{International Journal of Social Science and Economic Research}

strong influence on other sectors. For such sectors, we should start from the industry development mechanism, increase competition and improve market vitality. 5 sectors including Manufacture of Textiles belong to the 6th category, which have strong self-development ability, influence ability, but poor response ability. Manufacture of Food and Tobacco, Manufacture of Chemicals and Chemical Products, Production and Supply of Electricity and Steam belong to 7th category, with strong growth and poor spillover ability. Manufacture and Processing of Metals, Manufacture of Communication Equipment, Computer and Other Electronic Equipment belong to 8th category with strong growth and strong spillover ability. The improvement of their technical level is of great significance to the improvement of the overall level of China's industry.

The multiplier effect of the tertiary industry is lower than the social average. Except Wholesale and Retail Trade, Transport, Storage and Post, Finance, Renting and Leasing, Business Services, other sectors have weak response ability and poor growth. Except Accommodation, Food and Beverage Services, Scientific Research and Development, Technical Services, Health Care and Social Work Activities, Renting and Leasing, Business Services, other sectors have little influence ability. In this case, it is not ideal to rely on the pull of other industries. Therefore, for the tertiary industry, it is an urgent task to strengthen the construction of self-development mechanism, promote the optimization of industrial structure and give full play to industrial functions.

\section{CONCLUSION}

In this paper, the structure decomposition technology of multi-national and multi sector inputoutput model is applied to the analysis of a country's industrial structure problem. The industrial structure effect is divided into three parts: multiplier effect, feedback effect and spillover effect. On this basis, the characteristics of China's industrial association are investigated and the following important conclusions are drawn.

1. From the actual situation of China's industry as a whole, the importance of spillover effect, multiplier effect and feedback effect is decreasing in turn. The primary force of economic growth is the industry association mechanism, and the industry self-development mechanism also has an important influence. The industry feedback mechanism has relatively weak influence on the growth.

2. From the perspective of segmented industries, the primary industry has poor self-development ability and influence ability, but strong response ability. 17 secondary industrial sectors have lower self-development ability and response ability than the average level of the society, with poor growth, and 9 secondary industrial sectors have poor spillover ability. The overall selfdevelopment of the tertiary industry is poor, including 8 sectors with low growth and weak 
International Journal of Social Science and Economic Research

ISSN: $2455-8834$

Volume: 05, Issue: 03 "March 2020"

correlation.

These results show that the irrationality of China's industrial structure is not only the irrationality of industrial resource allocation, but also the poor self-development ability. Therefore, while adjusting the industrial structure with industrial policies, China must improve the market mechanism and promote the construction of the industrial viability, which is particularly important for the development of the tertiary industry.

\section{REFERENCES}

[1] $\mathrm{Li} \mathrm{Bo}, \mathrm{Hu}$ Jin. Comparative Analysis on the Measuring of Industrial Structure Optimization and Upgrading in China [J]. Journal of Management Sciences, 2008(02):8693.

[2] Liu Shuhan, Zhang Rui, Liu Lixia. Industry Relevancy Analysis of Producer Services and Manufacturing in China [J]. Nankai Economic Studies, 2010(06):65-74.

[3] Gao Chuansheng. A Study of Producer Services Role in Supporting Manufacturing in China: A Positive Research Based on China's Input-output Data [J]. Journal of Shan Xi Finance and Economics University, 2008(01):44-50.

[4] Wang Guojun, Liu Shuixing. The Driving Effects on Real Estate to the Correlative Industries [J]. Economic Research Journal, 2004(08):38-47.

[5] Song Zengwen. A Research in Industrial Correlation of China's Tourism Industry: Based on the Input-output Model [J]. Tourism Science, 2007(02):7-12+78.

[6] Li Jing, Zhang Shu-an, Liu Liwen. Environmental Costs and Determinants of Urban Residents' Consumption in China: Based on the Input-Output Analysis in Thirty Provincial-level Administrative Areas [J].East China Economic Management, 2018, 32 (12): 86-93.

[7] Sun Jianwei, Chen Zhigang, Zhao Rongqin, Huang Xianjin, Lai Li. Research on Carbon Emission Footprint of China Based on Input-output Model [J]. China Population, Resources and Environment, 2010,20(05):28-34.

[8] Liang Jinshe, Zheng Wei, Cai Jianming. The Decomposition of Energy Consumption Growth in China: Based on Input-output Model [J]. Journal of Natural Resources, 2007 (06): 853-864. 
[9] Zhang Zhihui, Liu Ruijie. Carbon emissions in the construction sector based on inputoutput analyses [J]. J Tsinghua Univ (Sci \& Tech), 2013, 53(01):53-57.

[10] Yu Dianfan, Gan Chunhui, Zheng Ruogu. Industrial Linkages in China: An Empirical Research Based on Structural Decomposition Technique of Input-output Model [J]. China Industrial Economics, 2011(11):5-15.

[11] Miller Ronald E., Blair Peter D. Input-output Analysis: Foundations and Extensions [M]. Cambridge University Press, 1985. 